\title{
Hyper-oncotic vs. Hypo-oncotic Albumin Solutions: a Systematic Review of Clinical Efficacy and Safety
}

\author{
Gary R. Haynes ${ }^{1}$ (D) Kayleigh Bassiri ${ }^{2}$
}

Accepted: 11 January 2021 / Published online: 5 March 2021

(C) The Author(s) 2021

\begin{abstract}
Several albumin solutions are available for volume expansion. Hyper-oncotic solutions $(\geq 20 \%)$ are more effective than hypooncotic $(\leq 5 \%)$ as they recruit endogenous extracellular fluid into blood vessels rather than adding volume. The latter may cause volume overload, with several associated complications. This systematic review aimed to evaluate evidence on the efficacy and safety of hyper-oncotic vs. hypo-oncotic albumin solutions across different clinical settings. The review was conducted according to PRISMA guidelines. Ninety articles were retained (58 randomized controlled trials). Four studies directly compared albumin solutions. SWIPE showed that cumulative fluid balance at $48 \mathrm{~h}$ was significantly lower with $20 \%$ vs. $5 \%$ albumin (mean $-576 \mathrm{~mL} ; P=0.01$ ). Twenty percent albumin was also associated with decreased chloride load vs. $4 \%$ albumin in critically ill patients. All 10 pre-/intraoperative studies evaluated 4-5\% solutions; 14 studies evaluated $4-5 \%$ albumin in postoperative patients. Renal injury was reported in some studies; however, hydroxyethyl starch was associated with higher incidence vs. albumin. Importantly, 20\% albumin preserved cumulative organ function in liver transplantation, and $25 \%$ albumin was more beneficial than saline in cardiac surgery patients. Thirty-two studies were performed in critically ill patients. Several studies reported increased risk of positive fluid balance and chloride load with hypo-oncotic albumin, whereas multiple benefits were associated with $20 \%$ albumin, including improved endothelial function and perfusion. Of 18 pediatric studies that evaluated $\leq 10 \%$ albumin, benefits such as correction of hypotension and improved cardiac output were noted. In conclusion, hyper-oncotic albumin solutions should be more routinely used to avoid potential risks associated with hypo-oncotic solutions.
\end{abstract}

Keywords Human albumin $\cdot$ Volume expansion $\cdot$ Fluid balance $\cdot$ Fluid therapy

\section{Introduction}

Intravenous fluids correct hypovolemia and increase cardiac preload, which leads to increased cardiac output, blood pressure, and effective organ perfusion [1]. Fluid resuscitation may be achieved using crystalloids such as saline or colloids such as albumin. Colloid solutions contain high-molecular weight components, which limits fluid movement from the intravascular space into the interstitium; therefore, colloids remain in the intravascular space longer than crystalloids [2].

This article is part of the Topical Collection on Medicine

Gary R. Haynes

ghaynes@tulane.edu

1 Department of Anesthesiology, Tulane University School of Medicine, 1430 Tulane Ave, New Orleans, LA 70112, USA

2 Meridian HealthComms, Plumley Moor Road, Plumley, UK
If rapid volume loss is observed, colloids retain intravascular volume more efficiently, leading to sustained systemic pressure compared with crystalloids [2]. Crystalloids have been associated with the risk of over-infusion and positive fluid balance, which can be life-threatening.

Albumin is an effective volume expander that can be used to achieve fluid resuscitation in several settings including sepsis [3], burns [4], and liver disease [5]. Several albumin solutions are available: $\leq 5 \%, 10-20 \%$, and 25\%. Hyper-oncotic solutions $(\geq 20 \%)$ are more effective than iso-/hypo-oncotic solutions $(\leq 5 \%)$ for the rapid expansion of plasma volume. Hyper-oncotic solutions stimulate the movement of endogenous extracellular fluids into the patients' blood vessels, as opposed to adding more volume [6], which can increase the risk of volume overload.

Positive fluid balance is a significant risk factor for cardiovascular complications [7]. Fluid overload can increase left ventricular end-diastolic volume beyond the heart's ability to eject blood and maintain stroke volume, which can lead to 
congestive heart failure [8]. Volume overload also reduces perfusion to the kidneys and urine production, which exacerbates the adverse effects [9]. Tsai et al. showed that for every $1 \%$ increase in hydration status, the risk for cardiovascular morbidity or all-cause mortality increased by $8 \%$ in patients with chronic kidney disease [8]. Pulmonary edema may also occur and can lengthen time on mechanical ventilation [10], intensive care unit (ICU) stay [11], and hospital stay overall [12]. It is also associated with edema of vital organs [13], intra-abdominal hypertension [14], and mortality [15].

The aim of this systematic review was to appraise the available evidence for hyper-oncotic vs. hypo-oncotic albumin solutions and evaluate whether the former should be used more routinely given the risk of positive fluid balance associated with the latter, which can lead to adverse events. The research question was as follows: "In patients receiving volume therapy, are there any advantages of hyper-oncotic, low-volume albumin solutions compared with hypo-oncotic, highvolume solutions, with regards to clinical efficacy and/or safety?".

\section{Methods}

\section{Search Strategy}

Published clinical data were sourced on 2 January 2020 on PubMed using the following search phrase: ("4\% albumin" or "5\% albumin" or "20\% albumin" or " $25 \%$ albumin" or "albu$\min 4 \%$ " or "albumin $5 \%$ " or "albumin $20 \%$ " or "albumin $25 \%$ " or "albumin infusion" or "albumin solution" or "albumin products" or "intravenous albumin") AND (critical care unit or critically ill or ICU or sepsis or septic shock or burns or trauma or "cardiac surgery" or "abdominal surgery" or "kidney transplant") (Table 1). A supplementary search of Embase was performed using the same search terms. This systematic review was conducted according to the PRISMA guidelines [16].

\section{Selection of Studies}

The titles and abstracts of all retrieved articles were assessed. Relevance was defined according to the inclusion and exclusion criteria listed in Online Resource 1. Any discrepancies were resolved by discussion between the authors. In cases of uncertainty, the article was retained for full-text analysis, and articles meeting any of the exclusion criteria were rejected from the evidence base. Liver disease was excluded because $20 \%$ albumin is already well established in this setting and several guidelines recommend its use. The literature was further restricted to human studies and those published in English; review articles (narrative or systematic) were excluded.

\section{Data Extraction and Assessment}

For all articles that met the eligibility criteria, the full texts were examined and the following data were extracted, where available: study population/setting, interventions, hemodynamic data, fluid balance, conclusions, and relevant safety data. All retained articles were assigned a study type. For example, if the investigators observed individuals without manipulation or intervention, the article was classified as an observational study; if investigators intervened and looked at the effects of an intervention on an outcome in a randomized casecontrolled cohort, it was classified as a randomized controlled trial (RCT). In addition, all retained articles underwent grading and bias assessment using the Scottish Intercollegiate Guidelines Network (SIGN) grading system [17], whereby the quality of individual studies is defined based on study design and methodological robustness (Online Resource 2). This process included evaluation of the study design, data
Table 1 Electronic search and filters/limits applied

\begin{tabular}{|c|c|c|}
\hline \# & Topic & Search \\
\hline 1 & Albumin terms & $\begin{array}{l}\text { (“4\% albumin" or " } 5 \% \text { albumin" or " } 20 \% \text { albumin" or } \\
\text { " } 25 \% \text { albumin" or "albumin } 4 \% \text { " or "albumin } 5 \% \text { " or } \\
\text { "albumin } 20 \% \text { " or "albumin } 25 \% \text { " or "albumin infusion" } \\
\text { or "albumin solution" or "albumin products" or "intravenous } \\
\text { albumin") }\end{array}$ \\
\hline 2 & Clinical setting terms & $\begin{array}{l}\text { (critical care unit or critically ill or ICU or sepsis or septic } \\
\text { shock or burns or trauma or "cardiac surgery" or } \\
\text { "abdominal surgery" or "kidney transplant") }\end{array}$ \\
\hline 3 & Combined search strategy & 1 and 2 \\
\hline \multicolumn{3}{|c|}{ Filters applied: } \\
\hline 1 & Type of study & Clinical trials and observational studies \\
\hline 2 & Participants & Human \\
\hline 3 & Language & English \\
\hline
\end{tabular}

$I C U$ intensive care unit 
analysis, and reporting of outcomes, and studies were judged to have a low, acceptable, or high risk of bias.

\section{Results}

\section{Overview of Included Studies}

The PubMed search yielded 455 unique citations, of which 76 were retained as relevant after checking against the eligibility criteria. An additional 14 relevant articles were retained from the Embase search.

Figure 1 depicts a PRISMA flow diagram detailing the reasons for exclusion and the eventual inclusion of the 90 articles that formed the evidence base for this systematic review. There were 89 studies in patients and one study in healthy volunteers. Of the 89 patient studies, $36 \%$ were conducted in the setting of critical illness, $36 \%$ were in surgical settings, $6 \%$ were in burns/ other settings, and $22 \%$ were in pediatric patients across all settings. The proportion of patient studies looking at each percentage albumin solution are shown in Table 2, arranged by indication; some studies were conducted across multiple settings. There were 58 RCTs, 10 non-randomized trials, 15 observational studies, and six other studies.
Across all settings, most of the 89 retained studies in patients were RCTs. Figure 2 shows the breakdown of study type by clinical setting. Quality and bias assessment of all retained studies is provided in Online Resource 2. In summary, there were 16 studies across the evidence base with a very low risk of bias, 63 with a low risk, and 10 with a high risk. Of the 58 RCTs in the evidence base, 10 had a very low risk of bias, 40 had a low risk, and eight had a high risk of bias. Studies of albumin in pediatric patients were the highest quality overall, including 16 RCTs, and all the evidence had either a low or a very low risk of bias. Most studies were performed in critically ill patients, which included 20 RCTs, six nonrandomized trials, two observational studies, and four other studies including one post hoc analysis. In the evidence base for critically ill patients, three studies had a very low risk of bias, 25 had low risk, and four had high risk.

\section{Hyper-oncotic vs. Hypo-oncotic Albumin}

There were four direct comparisons of albumin solutions, of which two studies had a very low risk of bias and two had a low risk of bias. The SWIPE RCT compared 5\% with $20 \%$ albumin [18]. The authors reported that the cumulative volume of fluid administered at $48 \mathrm{~h}$ was lower in the $20 \%$ group

Fig. 1 PRISMA flow diagram
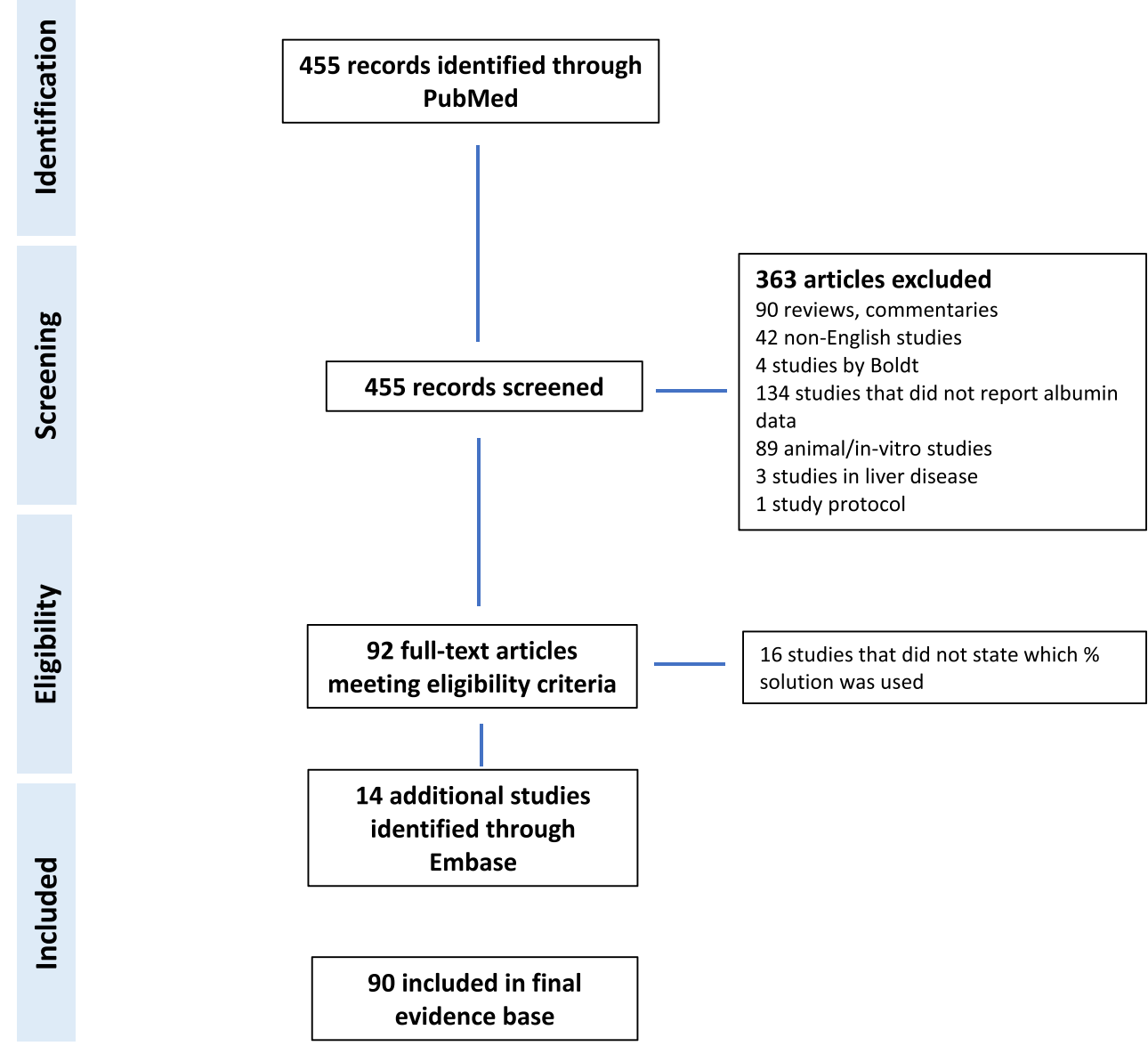
Table 2 Proportion of 89 studies on patients for each albumin category by indication

\begin{tabular}{|c|c|c|}
\hline Albumin solution $(\%)$ & Number of studies (\%) & Number of patients \\
\hline \multicolumn{3}{|c|}{ Surgery (postoperative; $N=22$ )) } \\
\hline $4-5$ & $14(64)$ & \multirow[t]{4}{*}{11,852} \\
\hline 20 & $5(23)$ & \\
\hline 25 & $2(9)$ & \\
\hline 4 and 20 & $1(4)$ & \\
\hline \multicolumn{3}{|c|}{ Surgery (pre-/intraoperative; $N=10$ ) } \\
\hline $4-5$ & $10(100)$ & 243 \\
\hline \multicolumn{3}{|l|}{ Critical illness $(N=32)$} \\
\hline $4-5$ & $14(44)$ & \multirow[t]{4}{*}{4342} \\
\hline 20 & $10(31)$ & \\
\hline 25 & $7(22)$ & \\
\hline 4 and 20 & $1(3)$ & \\
\hline \multicolumn{3}{|l|}{ Burns $(N=5)$} \\
\hline $2.5-5$ & $4(80)$ & \multirow[t]{2}{*}{173} \\
\hline 20 & $1(20)$ & \\
\hline \multicolumn{3}{|l|}{ Pediatric $(N=20)$} \\
\hline $4-5$ & $16(80)$ & \multirow[t]{4}{*}{1784} \\
\hline $10-20$ & $2(10)$ & \\
\hline 25 & $1(5)$ & \\
\hline 3 and 5 & $1(5)$ & \\
\hline
\end{tabular}

than in the $4-5 \%$ group (median difference $-600 \mathrm{~mL}, 95 \% \mathrm{CI}$ -800 to $-400, P<0.001$ ). Cumulative fluid balance was also significantly lower in the $20 \%$ group at $48 \mathrm{~h}$ (mean difference $-576 \mathrm{~mL}, 95 \% \mathrm{CI}-1033$ to $-119 ; P=0.01)$. Sodium and chloride levels were higher in the 4-5\% group, and time spent on mechanical ventilation was numerically higher in this group (15.3 vs. $12.0 \mathrm{~h}$ in the $4-5 \%$ and $20 \%$ groups, respectively) [18]. Similarly, Mcllroy et al. looked at the benefits of a chloride-restrictive strategy, comparing a chloride-rich $4 \%$ albumin solution with a chloride-limited $20 \%$ solution in a nonrandomized trial. While they found a significant difference between postoperative chloride load (210 [138-305] vs. 173
[122-239]) in the chloride-rich and chloride-limited groups, respectively, there was no significant increase in the occurrence of acute kidney injury (AKI) in the chloride-rich group. The number of cases of AKI in this group was, however, numerically higher compared with the group who received the chloride-limited $20 \%$ solution $(188$ [33.3\%] vs. 163 [29.1\%]) [19].

In an RCT, Yu et al. showed that patients who received 5\% albumin had significantly decreased positive fluid balance compared with patients who received $3 \%$ albumin following cardiopulmonary bypass (CPB) $(-5.4 \pm 9.1$ vs. $1.9 \pm 10.0$; $P<0.05)[20]$.

In a study of healthy volunteers by Bihari et al., $4 \%$ and $20 \%$ albumin solutions were both found to be more effective than saline or Hartmann's solution for increasing cardiac output and stroke volume, with reduced afterload. The albumin solutions were also safer; there was no evidence for interstitial pulmonary edema, an adverse event that was associated with saline and Hartmann's solution. The authors concluded that $20 \%$ albumin had a similar efficacy and adverse effect profile to $4 \%$ albumin at the equivalent dose (representing an $80 \%$ smaller administered volume) and that bolus administration of $20 \%$ albumin is safe and effective in healthy subjects. AKI was not observed with any of the resuscitation fluids, although the authors highlighted that this adverse event may only occur in patients already at risk for this adverse event or require longer to manifest than the timepoint used in this study (completion of infusion) [21].

\section{Efficacy of Albumin Before and During Surgery}

All 10 pre- and intraoperative studies of albumin evaluated 4 $5 \%$ solutions [22-31]. Of the 10 pre- and intraoperative studies, five studies were RCTs with a low risk of bias, and three studies were RCTs with a high risk of bias. Overall, $\leq 5 \%$ solutions were shown to be well tolerated and effective, particularly for maintenance of hemodynamic parameters and

\section{Study types by clinical setting}

patients by clinical setting showing that most retained studies were in critically ill patients (36\%) and the majority of studies across all clinical settings were RCTs (65\%). RCT, randomized controlled trial

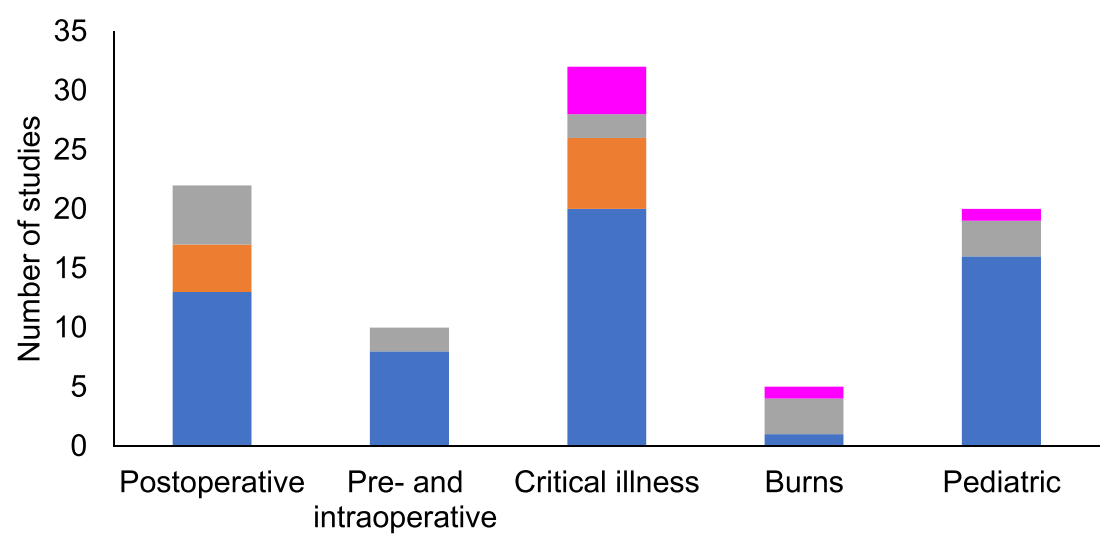

RCT Non-randomized Observational $\quad$ Other 
hemostasis [22-24, 29]. However, Payen et al. showed that $4 \%$ albumin increased the rate of fluid extravasation that impeded the maintenance of isovolemia [30]. Rex et al. reported similar findings; $4 \%$ albumin reduced fluid shift in the interstitium when compared with crystalloids [31]. In an observational study, Li et al. showed that albumin was effective in patients undergoing neurosurgery, provided that the volume infused was restricted [28].

Arellano reported that although some patients in both the hydroxyethyl starch (HES) group and the 5\% albumin group required allogenic transfusions, there were a higher number reported in the HES group [22]. Similarly, Hand et al. showed that renal injury occurred in a significantly larger proportion of patients who received HES compared with albumin ( 38 vs. $22 \%$; $P=0.048$ ) in a retrospective observational study [25]. However, Hand et al. did not distinguish between volume resuscitation to treat acute blood loss or other volume deficits, and ongoing fluid maintenance, which may have affected the outcome of this study [32]. Furthermore, the degree of acidosis observed in an RCT by Kwak and colleagues was more prominent in the patients that received HES [27]. In a further RCT, Kammerer and colleagues reported that $35 \%$ of patients receiving $5 \%$ albumin met the criteria for chronic kidney disease and suggested that albumin has a safety profile comparable with HES. However, it must be noted that patients in the albumin group had higher baseline American Society of Anesthesiologists (ASA) status that might have affected this outcome [26].

\section{Efficacy of Albumin After Surgery}

In total, 22 studies of postoperative patients were retained in the evidence base. Six studies were at a very low risk of bias, 14 at a low risk, and two at a high risk. Fourteen studies evaluated $4-5 \%$ albumin solutions in postoperative patients [33-46]. In RCTs by Scott and Zetterstrom, it was shown that less 5\% albumin solution is required for volume expansion compared with crystalloids [41, 44]. Consistent with this, an RCT performed by Verheij showed that albumin is better retained in the vasculature compared with crystalloids due to higher colloid osmotic pressure (COP) [43]. Statkevicius et al. reported that infusion of $5 \%$ albumin $(10 \mathrm{~mL} / \mathrm{kg}$ dose $)$ at slow (180 $\mathrm{min}$ ) versus fast (30 $\mathrm{min}$ ) infusion rates resulted in the same degree of volume expansion in patients with signs of hypoperfusion after major abdominal surgery in an RCT [45]. This suggests that from an efficacy point of view, rapid infusion may be preferable for faster volume expansion without sacrificing total volume expansion, taking into account the safety consideration of stopping the infusion at the first signs of hypervolemia.

An observational study by Opperer et al. showed that infusion of 5\% albumin leads to increased risk of renal failure compared with no albumin (odds ratio (OR) 1.56 [95\% CI 1.36-1.78]), following elective joint arthroplasty [39].
However, given that this was an observational study, and therefore patients were not randomly allocated to treatment, it is difficult to identify a causative association [47]. In a retrospective observational study, Hosseinzadeh et al. showed that while 5\% albumin and HES both caused an increase in serum creatinine when used as CPB priming fluid, the difference was significantly higher with HES at $72 \mathrm{~h}(0.33 \pm 0.13$ vs. $0.22 \pm 0.10[P<0.001]$ for HES and albumin, respectively) [35]. Furthermore, an observational study by Varelmann et al. found no difference in serum creatine or occurrence of AKI for patients treated with $5 \%$ albumin versus conventional CPB priming fluid, and significantly less fluid was infused in the albumin group [46]. A propensity-score matched study by Kingeter et al. reported that $5 \%$ albumin was associated with a decreased risk of mortality (OR 0.5 ; $95 \%$ CI $0.3-0.9, P=$ 0.02 ) and lower rate of 30-day readmission (OR $0.7 ; 98.3 \%$ CI, 0.5-0.9; $P=0.01$ ), compared with crystalloids [36].

Non-randomized trials by Hasselgren and Hahn both reported that $20 \%$ albumin has a sustained effect on plasma volume expansion with no adverse effects [48, 49]. Results from the HAS FLAIR study showed that administration of $20 \%$ albumin after cardiac surgery was equivalent to crystalloids (saline and/ or Hartmann's solution) in terms of cardiovascular optimization, with smaller volumes of fluid required and less positive cumulative balance. Lower amounts of vasopressor were delivered, and shorter durations of vasopressor therapy were required with $20 \%$ albumin versus crystalloids [50]. Following liver transplantation, $20 \%$ albumin was shown to preserve cumulative organ function as evidenced by a significantly lower SOFA score compared with patients who received no albumin (11.0 \pm 3.6 vs. $13.4 \pm 3.7 ; P<0.001$ for albumin vs. no albumin, respectively) [51]. Although Bruegger et al. reported a mild acidosis in response to $20 \%$ albumin infusion in an RCT, the study included only eight patients, and no other safety or efficacy outcomes were reported [52].

There were two studies of 25\% albumin in postoperative patients, both of which were RCTs. Magder et al. reported an inotropic effect following CPB that was more pronounced compared with patients who received saline [6], while Golub et al. suggested that $25 \%$ albumin offers no advantage in the ICU compared with standard nutritional support [53]. Importantly, seven patients included in the albumin group did not receive albumin or received less than required by the protocol; therefore, the overall findings may be misleading.

\section{Efficacy of Albumin in Critically III Patients}

There were 32 studies of critically ill patients retained in the evidence base, of which 20 were RCTs [18, 33, 54-83]. Of the 32 studies of critically ill patients, three studies had a very low risk of bias, 25 had a low risk, and four had a high risk of bias. There were 14 studies of $4-5 \%$ albumin $[33,55,60,61,63$, $64,66,69,74-78,82,83]$, of which several found that these 
solutions are generally well tolerated $[61,64,66,69,74,75]$. Two studies found that $5 \%$ albumin is effective at raising COP $[66,69]$, while Friedman et al. reported that $4 \%$ albumin raises cardiac index [64]. Fernandes and colleagues showed that 5\% albumin may enhance gastric perfusion in an RCT, which can help to improve symptoms in patients with sepsis [61].

Importantly, Ernest et al. reported that in an RCT, 5\% albumin stimulated the movement of fluid from the vasculature into the extravascular space, which may increase the risk of edema [33]. Similarly, Falk et al. showed that 5\% albumin is associated with positive fluid balance that leads to cardiac dysfunction in an RCT [60]. Studies by Finfer, Bellomo, and Spolestra-de Man reported that 4-5\% albumin solutions led to increased chloride load, but to a lesser degree than saline solutions $[55,63,76]$. However, the study by Finfer et al. was not designed to show the beneficial effect of albumin administration and, as a result, the sub-group analysis by Bellomo et al. is limited by the retrospective nature and the unmatched study cohorts [84, 85]. Park et al. found no significant improvement in 7-day survival when $4 \%$ albumin was added to lactated Ringer's solution versus lactated Ringer's alone, when used as early sepsis therapy in an RCT of patients with cancer. The authors cautioned, however, that their study may have been underpowered for this endpoint [83].

Overall, 17 studies reported on the efficacy and/or safety of $20-25 \%$ albumin solutions in critically ill patients $[54,56-59$, $62,65,67,68,70-73,79-82]$. In total, ten studies were RCTs and five were non-randomized trials. Ten of these studies evaluated $20 \%$ albumin, and all identified beneficial effects, including raised COP [80], improved endothelial function [65], improved perfusion [68], and increased plasma thiols leading to reduced oxidative stress [72]. A further four studies reported decreased positive fluid balance in response to $20 \%$ albumin [54, 56-58]. Bannard-Smith et al. and Hariri et al. also showed that $20 \%$ albumin lowers chloride levels compared with saline [65]. Of the seven studies that evaluated $25 \%$ albumin $[59,62,70,73,79,81,82]$, the majority showed that it was effective overall leading to improved cardiac index [81] and improved plasma thiol-dependent antioxidant status [73]. An RCT by Foley et al. suggested that albumin offers no survival advantage in the ICU compared with no albumin supplementation and is not cost-effective [82]. However, they included only 18 patients in the $25 \%$ albumin treatment group, and these patients achieved a normal serum albumin level in significantly fewer days compared with no treatment (4.2 vs. 9.0; $P<0.01)[82]$.

\section{Efficacy of Albumin in Patients with Burns}

There were five studies of patients with burns, three of which evaluated 2.5-5\% albumin solutions [86-89]. One study had a very low risk of bias and three had a low risk. Beneficial effects of albumin included reduced fluid creep [88] and reduced time on mechanical ventilation [89]. In contrast, an RCT by Goodwin et al. showed that $2.5 \%$ albumin infusion leads to accumulation of lung water, suggesting that crystalloids alone may lead to better outcomes in this patient population. In an observational study, Blanco-Schweizer et al. reported on the fluid resuscitation of burns patients using a variable ratio of $20 \%$ albumin to lactated Ringer's solution, where the proportion of $20 \%$ albumin was decreased every $8 \mathrm{~h}$. The volume of fluid administered was found to be relatively low compared with other studies. Fluid resuscitation was successful with this approach, showing significant base excess increase (120\%) and lactate clearance $(29 \%)$ [90].

\section{Efficacy of Albumin in Pediatric Patients}

There were 20 studies of pediatric patients retained in the evidence base. In total, five studies had a very low risk of bias, 13 had a low risk, and one had a high risk of bias. Of the 18 studies that evaluated $\leq 10 \%$ albumin solutions in pediatric patients [20,91-107], two identified beneficial effects, including reduced need for perioperative transfusions [98] and correction of hypotension and cardiac output [105]. In an RCT, Akech and colleagues showed that 5\% albumin is associated with a survival benefit in children with severe malaria [103]. In contrast, other studies showed that $\leq 5 \%$ albumin solutions can lead to adverse events such as acidosis, edema, creatinemia, pulmonary edema, and respiratory symptoms $[95,96,100,103,104,107]$. Both Dingankar and Van der Linden showed that administration of $5 \%$ albumin leads to positive fluid balance, resulting in increased days on mechanical ventilation and longer overall ICU stay. However, Müller Dittrich et al. showed that early administration (8-12 h) of 5\% albumin in pediatric patients with burns significantly reduced the length of hospital stay compared with later administration (24 h) (14 [10-17] vs. 18 [15-21]; $P=0.004)$ in an RCT [97]. An observational study by Gelbart et al. investigated the effects of fluid bolus treatment with $4 \%$ albumin, saline, or modified ultrafiltrate blood in pediatric patients who had undergone cardiac surgery including CPB (78\% of patients). Hemodynamic response to fluid bolus treatment was reported to be infrequent and unsustained. However, it was not investigated whether any of the three treatments was more effective than the others [106].

Loeffelbein et al. reported on the effects of $20 \%$ albumin in pediatric patients undergoing $\mathrm{CPB}$ in an RCT and found that it effectively raises oncotic pressure with no adverse effects on renal function or observed metabolic disturbance [108]. Greissman et al. evaluated the effects of bolus vs. continuous infusion of 25\% albumin in an RCT, finding that continuous albumin administration leads to sustained improvement in hypovolemia due to improved half-life compared with bolus infusion [109]. 


\section{Discussion}

In most studies included in this systematic review, albumin administration (all formulations) was shown to affect parameters which may indicate potential clinical benefit, including but not limited to the following: raised COP [80], improved endothelial function [65], improved perfusion [68], decreased positive fluid balance [54, 56-58], improved cardiac index [81], and improved plasma thioldependent antioxidant status [72, 73]. In addition, albumin administration was shown to provide clinical benefit in certain patient populations, for example, a decreased risk of mortality, lower rate of 30-day readmission, and reduced length of hospital stay $[36,97]$. Few studies directly compared different percentage albumin solutions; however, those that did identified a clear benefit of hyper-oncotic solutions compared with hypo-oncotic solutions, such as a decrease in the number of AKI cases, decreased chloride load and lower cumulative fluid balance [18, 19]. Benefits were observed even in a comparison between 3 and 5\% albumin, whereby the $3 \%$ solution led to more positive fluid balance in pediatric patients undergoing surgery [20]. Similarly, the investigators in the SWIPE trial concluded that resuscitation with $20 \%$ albumin reduces early fluid requirements and cumulative fluid balance, which are known to be associated with adverse effects [7-9]. These findings imply that larger randomized trials of $20 \%$ albumin in comparison with low-concentration albumin solutions are warranted. An ongoing trial (AlbAlsace; ClinicalTrials.gov Identifier: NCT02755155) is comparing $4 \%$ vs. $20 \%$ albumin in critically ill patients and is due to complete in mid-2021; the primary endpoint is 28 -day mortality.

While there were some studies that identified detrimental effects of albumin across different indications, it must be noted that albumin is often administered to more severely ill patients; thus, increased complications and mortality are more likely to be due to a mix of factors, and not solely attributable to albumin [88]. For instance, Opperer et al. reported a high prevalence of comorbidities, and the observational nature of the study means that confounding variables, such as patient characteristics and dosing, cannot be closely controlled [39]. Similarly, Kammerer et al. reported that albumin and HES led to comparable adverse effects; however, the patients in the albumin group had a higher ASA status and were more sick at baseline compared with the HES group [26].

In total, 64/89 studies in patients (72\%) were performed in critically ill patients and those undergoing surgery. Further studies are warranted in under-represented patient populations, particularly patients with burns, where only five studies were identified, with the majority of those evaluating $\leq 5 \%$ albumin solutions. A previous metaanalysis of albumin in patients with burns concluded that albumin has a neutral effect on mortality in patients with burns and called for a high-quality randomized trial due to limited evidence and uncertainty [110]. Importantly, there were only four studies included in their analysis, and all of these were of $\leq 5 \%$ albumin solutions; therefore, the efficacy of hyper-oncotic albumin solutions in patients with burns is yet to be properly addressed.

Albumin solutions contain differing concentrations of chloride; however, the effects of high-chloride concentrations remain unclear. Previous evidence showed that $4 \%$ albumin led to the development of lung edema [111], while a chloriderestrictive strategy was associated with a significant decrease in the incidence of AKI [112]. A number of studies included in this review show that hypo-oncotic albumin leads to metabolic acidosis in some patients $[19,63,96,100]$, whereas two studies highlighted the beneficial effects of hyper-oncotic albumin at limiting chloridemia and acidosis [56, 65]. Therefore, high-quality RCTs comparing hypo- and hyperoncotic albumin solutions are needed to firmly establish any detrimental effects that might impact physicians' choice of albumin solution.

Although $\leq 5 \%$ albumin solutions are the most extensively used across all indications (67\%), this review suggests that $20-25 \%$ formulations should be more widely adopted. In cardiac surgery particularly, hyper-oncotic solutions are preferable because postoperative patients often have an excess of extracellular volume, and hyper-oncotic albumin helps to mobilize their own fluid rather than add more volume, which would subsequently require removal [6]. Hyper-oncotic albumin solutions may also be preferable in hypoalbuminemic critically ill patients, as they result in a low positive fluid balance and a tolerance to enteral feeding, resulting in improved organ function [58]. In addition, hyper-oncotic albumin solutions are preferable in patients at risk of hyperchloremia, due to a lower perioperative chloride load than hypo-oncotic albumin solutions [19]. This systematic review also identified evidence of edema in response to hypo-oncotic albumin administration [22, 60, 86, 100], which warrants further investigation in adequately powered, largescale studies.

This review has several limitations. The search was limited to indications in which albumin is most commonly used; therefore, broadening the search to other indications that are less widely studied, e.g., plasma exchange, may identify additional relevant studies. Furthermore, we searched two leading medical publication databases (PubMed and Embase), although the inclusion of other databases may identified additional relevant publications. There were few studies in patients with burns, an area that warrants further research. The number of studies identified that directly compared albumin solutions was low, reflecting the relative lack of comparative literature at this time. Finally, many of the retained studies included low patient numbers, further highlighting the need for more large- 
scale studies, in a variety of clinical settings, directly comparing different percentage albumin solutions.

This systematic review of clinical evidence published to date indicates beneficial effects of hyper-oncotic albumin compared with hypo-oncotic solutions, despite a paucity of studies directly comparing the two. While albumin solutions are generally efficacious, less fluid is required when more concentrated, hyper-oncotic formulations are used. In direct comparison studies, the cumulative volume of fluid, cumulative fluid balance, sodium and chloride levels, time spent on mechanical ventilation, and total number of cases of AKI were lower in patients administered hyperoncotic albumin, in comparison with patients administered hypo-oncotic albumin [18-20]. Low-percentage solutions more frequently cause pulmonary edema and have been associated with increased risk of chloridemia and metabolic acidosis.

Based on the data identified in this systematic review, routine use of high-percentage, hyper-oncotic albumin solutions could avoid the potential risks associated with positive fluid balance. Fluid resuscitation is a bedside art, and not a "onesize-fits-all" treatment [2]. Clinical decision-making should be tailored to the individual patient where possible to ensure the most effective use of fluid therapy and the best outcomes for patients.

Supplementary Information The online version contains supplementary material available at https://doi.org/10.1007/s42399-021-00755-0.

Authors' Contributions GH: This author contributed to the concept and design of the systematic review and the interpretation of the included evidence, revised the work for important intellectual content, approved the final version for publication, and agrees to be accountable for all aspects of the work.

KB: This author contributed to the concept and design of the systematic review and the interpretation of the included evidence, revised the work for important intellectual content, approved the final version for publication, and agrees to be accountable for all aspects of the work.

Funding This work was supported by CSL Behring. Editorial assistance was provided by Meridian HealthComms Ltd., funded by CSL Behring.

Data Availability Additional data are supplied as online resources.

\section{Compliance with Ethical Standards}

Conflict of Interest $\mathrm{GH}$ declares that he has no conflict of interest. KB was funded by CSL Behring.

Ethics Approval Not applicable.

Consent to Participate Not applicable.

Consent for Publication Not applicable.

Code Availability Not applicable.
Open Access This article is licensed under a Creative Commons Attribution 4.0 International License, which permits use, sharing, adaptation, distribution and reproduction in any medium or format, as long as you give appropriate credit to the original author(s) and the source, provide a link to the Creative Commons licence, and indicate if changes were made. The images or other third party material in this article are included in the article's Creative Commons licence, unless indicated otherwise in a credit line to the material. If material is not included in the article's Creative Commons licence and your intended use is not permitted by statutory regulation or exceeds the permitted use, you will need to obtain permission directly from the copyright holder. To view a copy of this licence, visit http://creativecommons.org/licenses/by/4.0/.

\section{References}

1. Bennett VA, Vidouris A, Cecconi M. Effects of fluids on the macro- and microcirculations. Crit Care. 2018;22(1):74.

2. Arshed S, Pinsky MR. Applied physiology of fluid resuscitation in critical illness. Crit Care Clin. 2018;34(2):267-77.

3. Delaney AP, Dan A, McCaffrey J, Finfer S. The role of albumin as a resuscitation fluid for patients with sepsis: a systematic review and meta-analysis. Crit Care Med. 2011;39(2):386-91.

4. Navickis RJ, Greenhalgh DG, Wilkes MM. Albumin in burn shock resuscitation: a meta-analysis of controlled clinical studies. J Burn Care Res. 2016;37(3):e268-78.

5. Kwok CS, Krupa L, Mahtani A, Kaye D, Rushbrook SM, Phillips MG, et al. Albumin reduces paracentesis-induced circulatory dysfunction and reduces death and renal impairment among patients with cirrhosis and infection: a systematic review and meta-analysis. Biomed Res Int. 2013;295153.

6. Magder S, Lagonidis D. Effectiveness of albumin versus normal saline as a test of volume responsiveness in post-cardiac surgery patients. J Crit Care. 1999;14(4):164-71.

7. Pipanmekaporn T, Punjasawadwong Y, Charuluxananan S, Lapisatepun W, Bunburaphong P, Saeteng S. Association of positive fluid balance and cardiovascular complications after thoracotomy for noncancer lesions. Risk Manag Healthc Policy. 2014;7:121-9.

8. Tsai YC, Chiu YW, Tsai JC, Kuo HT, Hung CC, Hwang SJ, et al. Association of fluid overload with cardiovascular morbidity and all-cause mortality in stages 4 and 5 CKD. Clin J Am Soc Nephrol. 2015;10(1):39-46.

9. Scales K, Pilsworth J. The importance of fluid balance in clinical practice. Nurs Stand (R Coll Nurs (Great Britain): 1987). 2008;22(47):50-7.

10. Vidal S, Perez A, Eulmesekian P. Fluid balance and length of mechanical ventilation in children admitted to a single pediatric intensive care unit. Archivos Argentinos de Pediatria. 2016;114(4):313-8.

11. Koonrangsesomboon W, Khwannimit B. Impact of positive fluid balance on mortality and length of stay in septic shock patients. Indian J Crit Care Med. 2015;19(12):708-13.

12. Koop AH, Stancampiano FF, Jackson J, Henry A, Horsley-Silva J, Pannala R, et al. Association of total fluid intake and output with duration of hospital stay in patients with acute pancreatitis. Gastroenterol Res Pract. 2018;2018:7614381.

13. Prowle JR, Echeverri JE, Ligabo EV, Ronco C, Bellomo R. Fluid balance and acute kidney injury. Nat Rev Nephrol. 2010;6(2): 107-15.

14. Malbrain ML, Marik PE, Witters I, Cordemans C, Kirkpatrick AW, Roberts DJ, et al. Fluid overload, de-resuscitation, and outcomes in critically ill or injured patients: a systematic review with 
suggestions for clinical practice. Anaesthesiol Intensive Ther. 2014;46(5):361-80.

15. Boyd JH, Forbes J, Nakada TA, Walley KR, Russell JA. Fluid resuscitation in septic shock: a positive fluid balance and elevated central venous pressure are associated with increased mortality. Crit Care Med. 2011;39(2):259-65.

16. Moher D, Liberati A, Tetzlaff J, Altman DG. Preferred reporting items for systematic reviews and meta-analyses: the PRISMA statement. PLoS Med. 2009;6(7):e1000097.

17. Harbour R, Miller J. A new system for grading recommendations in evidence based guidelines. BMJ (Clin Res Ed). 2001;323(7308):334-6.

18. Martensson J, Bihari S, Bannard-Smith J, Glassford NJ, LloydDonald P, Cioccari L, et al. Small volume resuscitation with $20 \%$ albumin in intensive care: physiological effects : the SWIPE randomised clinical trial. Intensive Care Med. 2018;44(11): 1797-806.

19. McIlroy D, Murphy D, Kasza J, Bhatia D, Wutzlhofer L, Marasco S. Effects of restricting perioperative use of intravenous chloride on kidney injury in patients undergoing cardiac surgery: the LICRA pragmatic controlled clinical trial. Intensive Care Med. 2017;43(6):795-806.

20. Yu K, Liu Y, Hei F, Li J, Long C. Effect of different albumin concentrations in extracorporeal circuit prime on perioperative fluid status in young children. ASAIO J (Am Soc Artif Internal Organs : 1992). 2008;54(5):463-6.

21. Bihari S, Wiersema UF, Perry R, Schembri D, Bouchier T, Dixon D, et al. Efficacy and safety of $20 \%$ albumin fluid loading in healthy subjects: a comparison of four resuscitation fluids. J Appl Physiol (Bethesda, Md : 1985). 2019;126(6):1646-60.

22. Arellano R, Gan BS, Salpeter MJ, Yeo E, McCluskey S, Pinto R, et al. A triple-blinded randomized trial comparing the hemostatic effects of large-dose $10 \%$ hydroxyethyl starch $264 / 0.45$ versus $5 \%$ albumin during major reconstructive surgery. Anesth Analg. 2005;100(6):1846-53.

23. Choi YS, Shim JK, Hong SW, Kim JC, Kwak YL. Comparing the effects of 5\% albumin and 6\% hydroxyethyl starch 130/0.4 on coagulation and inflammatory response when used as priming solutions for cardiopulmonary bypass. Minerva Anestesiol. 2010;76(8):584-91.

24. Engel JM, Welters I, Rupp M, Langefeld T, Ruwoldt R, Menges $\mathrm{T}$, et al. Influence of colloid fluids on polymorphonuclear granulocyte function in vivo. Acta Anaesthesiol Scand. 2001;45(3): 385-9.

25. Hand WR, Whiteley JR, Epperson TI, Tam L, Crego H, Wolf B, et al. Hydroxyethyl starch and acute kidney injury in orthotopic liver transplantation: a single-center retrospective review. Anesth Analg. 2015;120(3):619-26.

26. Kammerer T, Brettner F, Hilferink S, Hulde N, Klug F, Pagel J, et al. No differences in renal function between balanced $6 \%$ hydroxyethyl starch (130/0.4) and 5\% albumin for volume replacement therapy in patients undergoing cystectomy: a randomized controlled trial. Anesthesiology. 2018;128(1):67-78.

27. Kwak HJ, Lim OK, Baik JM, Jo YY. Acid/base alterations during major abdominal surgery: $6 \%$ hydroxyethyl starch infusion versus 5\% albumin. Korean J Anesthesiol. 2018;71(6):459-66.

28. Li N, Statkevicius S, Asgeirsson B, Schott U. Effects of different colloid infusions on ROTEM and Multiplate during elective brain tumour neurosurgery. Perioperative Med (Lond, Engl). 2015;4:9.

29. Mastroianni L, Low HB, Rollman J, Wagle M, Bleske B, Chow MS. A comparison of $10 \%$ pentastarch and $5 \%$ albumin in patients undergoing open-heart surgery. J Clin Pharmacol. 1994;34(1):34 40.

30. Payen JF, Vuillez JP, Geoffray B, Lafond JL, Comet M, Stieglitz $\mathrm{P}$, et al. Effects of preoperative intentional hemodilution on the extravasation rate of albumin and fluid. Crit Care Med. 1997;25(2):243-8.

31. Rex S, Scholz M, Weyland A, Busch T, Schorn B, Buhre W. Intra- and extravascular volume status in patients undergoing mitral valve replacement: crystalloid vs. colloid priming of cardiopulmonary bypass. Eur J Anaesthesiol. 2006;23(1):1-9.

32. Greenberg S, Tung A. But is it safe? Hydroxyethyl starch in perioperative care. Anesth Analg. 2015;120(3):519-21.

33. Ernest D, Belzberg AS, Dodek PM. Distribution of normal saline and 5\% albumin infusions in septic patients. Crit Care Med. 1999;27(1):46-50.

34. Gondos T, Marjanek Z, Ulakcsai Z, Szabo Z, Bogar L, Karolyi M, et al. Short-term effectiveness of different volume replacement therapies in postoperative hypovolaemic patients. Eur J Anaesthesiol. 2010;27(9):794-800.

35. Hosseinzadeh Maleki M, Derakhshan P, Rahmanian Sharifabad A, Amouzeshi A. Comparing the effects of 5\% albumin and 6\% hydroxyethyl starch 130/0.4 (Voluven) on renal function as priming solutions for cardiopulmonary bypass: a randomized double blind clinical trial. Anesthesiol Pain Med. 2016;6(1):e30326.

36. Kingeter AJ, Raghunathan K, Munson SH, Hayashida DK, Zhang $\mathrm{X}$, Iyengar S, et al. Association between albumin administration and survival in cardiac surgery: a retrospective cohort study. Can J Anaesth = Journal Canadien D'anesthesie. 2018;65(11):1218-27.

37. Moggio RA, Rha CC, Somberg ED, Praeger PI, Pooley RW, Reed GE. Hemodynamic comparison of albumin and hydroxyethyl starch in postoperative cardiac surgery patients. Crit Care Med. 1983;11(12):943-5.

38. Niemi TT, Suojaranta-Ylinen RT, Kukkonen SI, Kuitunen AH. Gelatin and hydroxyethyl starch, but not albumin, impair hemostasis after cardiac surgery. Anesth Analg. 2006;102(4):9981006.

39. Opperer M, Poeran J, Rasul R, Mazumdar M, Memtsoudis SG. Use of perioperative hydroxyethyl starch $6 \%$ and albumin $5 \%$ in elective joint arthroplasty and association with adverse outcomes: a retrospective population based analysis. BMJ (Clin Res Ed). 2015;350:h1567.

40. Schramko AA, Suojaranta-Ylinen RT, Kuitunen AH, Kukkonen SI, Niemi TT. Rapidly degradable hydroxyethyl starch solutions impair blood coagulation after cardiac surgery: a prospective randomized trial. Anesth Analg. 2009;108(1):30-6.

41. Scott DA, Hore PJ, Cannata J, Masson K, Treagus B, Mullaly J. A comparison of albumin, polygeline and crystalloid priming solutions for cardiopulmonary bypass in patients having coronary artery bypass graft surgery. Perfusion. 1995;10(6):415-24.

42. Skhirtladze K, Base EM, Lassnigg A, Kaider A, Linke S, Dworschak M, et al. Comparison of the effects of albumin 5\%, hydroxyethyl starch 130/0.4 6\%, and Ringer's lactate on blood loss and coagulation after cardiac surgery. Br J Anaesth. 2014;112(2):255-64.

43. Verheij J, van Lingen A, Beishuizen A, Christiaans HM, de Jong JR, Girbes AR, et al. Cardiac response is greater for colloid than saline fluid loading after cardiac or vascular surgery. Intensive Care Med. 2006;32(7):1030-8.

44. Zetterstrom $\mathrm{H}$, Hedstrand U. Albumin treatment following major surgery. I. Effects on plasma oncotic pressure, renal function and peripheral oedema. Acta Anaesthesiol Scand. 1981;25(2):125-32.

45. Statkevicius S, Bonnevier J, Fisher J, Bark BP, Larsson E, Oberg $\mathrm{CM}$, et al. Albumin infusion rate and plasma volume expansion: a randomized clinical trial in postoperative patients after major surgery. Crit Care. 2019;23(1):191.

46. Varelmann D, Shook D, Buric D, Yadzchi F, Dinga Madou I, Morth K, et al. Enhanced recovery after cardiac surgery: fluid balance and incidence of acute kidney injury. J Cardiothorac Vasc Anesth. 2019;33(Suppl. 2):S141-2. 
47. Haase N, Perner A. Colloid solutions in the perioperative setting. BMJ (Clin Res Ed). 2015;350:h1656.

48. Hahn RG, Zdolsek M, Hasselgren E, Zdolsek J, Bjorne H. Fluid volume kinetics of $20 \%$ albumin. Br J Clin Pharmacol. 2019;85(6):1303-11.

49. Hasselgren E, Zdolsek M, Zdolsek JH, Bjorne H, Krizhanovskii C, Ntika S, et al. Long intravascular persistence of $20 \%$ albumin in postoperative patients. Anesth Analg. 2019;129:1232-9.

50. Wigmore GJ, Anstey JR, St John A, Greaney J, Morales-Codina M, Presneill JJ, et al. 20\% human albumin solution fluid bolus administration therapy in patients after cardiac surgery (the HAS FLAIR study). J Cardiothorac Vasc Anesth. 2019;33(11):2920-7.

51. Ertmer C, Kampmeier TG, Volkert T, Wolters H, Rehberg S, Morelli A, et al. Impact of human albumin infusion on organ function in orthotopic liver transplantation-a retrospective matched-pair analysis. Clin Transpl. 2015;29(1):67-75.

52. Bruegger D, Jacob M, Scheingraber S, Conzen P, Becker BF, Finsterer U, et al. Changes in acid-base balance following bolus infusion of $20 \%$ albumin solution in humans. Intensive Care Med. 2005;31(8):1123-7.

53. Golub R, Sorrento JJ Jr, Cantu R Jr, Nierman DM, Moideen A, Stein HD. Efficacy of albumin supplementation in the surgical intensive care unit: a prospective, randomized study. Crit Care Med. 1994;22(4):613-9.

54. Bannard-Smith J, Alexander P, Glassford N, Chan MJ, Lee M, Wong BT, et al. Haemodynamic and biochemical responses to fluid bolus therapy with human albumin solution, $4 \%$ versus 20\%, in critically ill adults. Crit Care Resusc. 2015;17(2):122-8.

55. Bellomo R, Morimatsu H, French C, Cole L, Story D, Uchino S, et al. The effects of saline or albumin resuscitation on acid-base status and serum electrolytes. Crit Care Med. 2006;34(12):28917.

56. Caironi P, Tognoni G, Masson S, Fumagalli R, Pesenti A, Romero $\mathrm{M}$, et al. Albumin replacement in patients with severe sepsis or septic shock. N Engl J Med. 2014;370(15):1412-21.

57. Dolecek M, Svoboda P, Kantorova I, Scheer P, Sas I, Bibrova J, et al. Therapeutic influence of $20 \%$ albumin versus $6 \%$ hydroxyethylstarch on extravascular lung water in septic patients: a randomized controlled trial. Hepato-gastroenterology. 2009;56(96):1622-8.

58. Dubois MJ, Orellana-Jimenez C, Melot C, De Backer D, Berre J, Leeman $\mathrm{M}$, et al. Albumin administration improves organ function in critically ill hypoalbuminemic patients: a prospective, randomized, controlled, pilot study. Crit Care Med. 2006;34(10):253640.

59. Erstad BL, Richards H, Rose S, Nakazato P, Fortune J. Influence of twenty-five per cent human serum albumin on total and ionized calcium concentrations in vivo. Crit Care. 1999;3(4):117-21.

60. Falk JL, Rackow EC, Astiz ME, Weil MH. Effects of hetastarch and albumin on coagulation in patients with septic shock. J Clin Pharmacol. 1988;28(5):412-5.

61. Fernandes CJ Jr, Akamine N, De Marco FV, De Souza JA, Lagudis S, Knobel E. Red blood cell transfusion does not increase oxygen consumption in critically ill septic patients. Crit Care. 2001;5(6):362-7.

62. Ferreira da Cunha D, Santana FH, Guiares Tachotti FJ, Freire de Carvalho da Cunha S. Intravenous albumin administration and body water balance in critically ill patients. Nutrition (Burbank, Los Angeles County, Calif). 2003;19(2):157-8.

63. Finfer S, Bellomo R, McEvoy S, Lo SK, Myburgh J, Neal $B$, et al. Effect of baseline serum albumin concentration on outcome of resuscitation with albumin or saline in patients in intensive care units: analysis of data from the saline versus albumin fluid evaluation (SAFE) study. BMJ (Clin Res Ed). 2006;333(7577):1044.
64. Friedman G, Jankowski S, Shahla M, Gomez J, Vincent JL. Hemodynamic effects of $6 \%$ and $10 \%$ hydroxyethyl starch solutions versus $4 \%$ albumin solution in septic patients. J Clin Anesth. 2008;20(7):528-33.

65. Hariri G, Joffre J, Deryckere S, Bige N, Dumas G, Baudel JL, et al. Albumin infusion improves endothelial function in septic shock patients: a pilot study. Intensive Care Med. 2018;44(5):669-71.

66. Haupt MT, Rackow EC. Colloid osmotic pressure and fluid resuscitation with hetastarch, albumin, and saline solutions. Crit Care Med. 1982;10(3):159-62.

67. Margarson MP, Soni NC. Effects of albumin supplementation on microvascular permeability in septic patients. J Appl Physiol (Bethesda, Md : 1985). 2002;92(5):2139-45.

68. Margarson MP, Soni NC. Changes in serum albumin concentration and volume expanding effects following a bolus of albumin 20\% in septic patients. Br J Anaesth. 2004;92(6):821-6.

69. Mbaba Mena J, De Backer D, Vincent JL. Effects of a hydroxyethylstarch solution on plasma colloid osmotic pressure in acutely ill patients. Acta Anaesthesiol Belg. 2000;51(1):39-42.

70. Oczkowski SJW, Klotz L, Mazzetti I, Alshamsi F, Chen ML, Foster G, et al. Furosemide and albumin for diuresis of edema (FADE): a parallel-group, blinded, pilot randomized controlled trial. J Crit Care. 2018;48:462-7.

71. Palumbo D, Servillo G, D'Amato L, Volpe ML, Capogrosso G, De Robertis E, et al. The effects of hydroxyethyl starch solution in critically ill patients. Minerva Anestesiol. 2006;72(7-8):655-64.

72. Quinlan GJ, Margarson MP, Mumby S, Evans TW, Gutteridge JM. Administration of albumin to patients with sepsis syndrome: a possible beneficial role in plasma thiol repletion. Clin Sci (Lond, Engl : 1979). 1998;95(4):459-65.

73. Quinlan GJ, Mumby S, Martin GS, Bernard GR, Gutteridge JM, Evans TW. Albumin influences total plasma antioxidant capacity favorably in patients with acute lung injury. Crit Care Med. 2004;32(3):755-9.

74. Rackow EC, Falk JL, Fein IA, Siegel JS, Packman MI, Haupt MT, et al. Fluid resuscitation in circulatory shock: a comparison of the cardiorespiratory effects of albumin, hetastarch, and saline solutions in patients with hypovolemic and septic shock. Crit Care Med. 1983;11(11):839-50.

75. Rackow EC, Mecher C, Astiz ME, Griffel M, Falk JL, Weil MH. Effects of pentastarch and albumin infusion on cardiorespiratory function and coagulation in patients with severe sepsis and systemic hypoperfusion. Crit Care Med. 1989;17(5):394-8.

76. Spoelstra-de Man AM, Smorenberg A, Groeneveld AB. Different effects of fluid loading with saline, gelatine, hydroxyethyl starch or albumin solutions on acid-base status in the critically ill. PLoS One. 2017;12(4):e0174507.

77. Stockwell MA, Scott A, Day A, Riley B, Soni N. Colloid solutions in the critically ill. A randomised comparison of albumin and polygeline 2 . Serum albumin concentration and incidences of pulmonary oedema and acute renal failure. Anaesthesia. 1992;47(1): 7-9.

78. Stockwell MA, Soni N, Riley B. Colloid solutions in the critically ill. A randomised comparison of albumin and polygeline. 1. Outcome and duration of stay in the intensive care unit. Anaesthesia. 1992;47(1):3-6.

79. Tomita H, Ito U, Tone O, Masaoka H, Tominaga B. High colloid oncotic therapy for contusional brain edema. Acta Neurochir Suppl (Wien). 1994;60:547-9.

80. Veneman TF, Oude Nijhuis J, Woittiez AJ. Human albumin and starch administration in critically ill patients: a prospective randomized clinical trial. Wien Klin Wochenschr. 2004;116(9-10): 305-9.

81. Walkinshaw M, Shoemaker WC. Use of volume loading to obtain preferred levels of PEEP. A preliminary study. Crit Care Med. 1980;8(2):81-6. 
82. Foley EF, Borlase BC, Dzik WH, Bistrian BR, Benotti PN. Albumin supplementation in the critically ill. A prospective, randomized trial. Arch Surg (Chicago, Ill : 1960). 1990;125(6):739 42.

83. Park CHL, de Almeida JP, de Oliveira GQ, Rizk SI, Fukushima JT, Nakamura RE, et al. Lactated Ringer's versus $4 \%$ albumin on lactated Ringer's in early sepsis therapy in cancer patients: a pilot single-center randomized trial. Crit Care Med. 2019;47(10):e798 805 .

84. Shapiro MJ, Fitzgerald DA. Fresh water versus salt water: when will the seas meet! Crit Care Med. 2006;34(12):3036-7.

85. Vincent JL. Resuscitation using albumin in critically ill patients: research in patients at high risk of complications is now needed. BMJ (Clin Research Ed). 2006;333(7577):1029-30.

86. Goodwin CW, Dorethy J, Lam V, Pruitt BA Jr. Randomized trial of efficacy of crystalloid and colloid resuscitation on hemodynamic response and lung water following thermal injury. Ann Surg. 1983;197(5):520-31.

87. Gore DC, Dalton JM, Gehr TW. Colloid infusions reduce glomerular filtration in resuscitated burn victims. J Trauma. 1996;40(3): 356-60.

88. Lawrence A, Faraklas I, Watkins H, Allen A, Cochran A, Morris $\mathrm{S}$, et al. Colloid administration normalizes resuscitation ratio and ameliorates "fluid creep". J Burn Care Res. 2010;31(1):40-7.

89. Park SH, Hemmila MR, Wahl WL. Early albumin use improves mortality in difficult to resuscitate burn patients. J Trauma Acute Care Surg. 2012;73(5):1294-7.

90. Blanco-Schweizer P, Sanchez-Ballesteros J, Bendito B, Martin AI, Fernandez L, Piqueras JM et al. Resuscitation with albumin using BET formula keeps at bay fluid administration in burned patients. An observational study. Burns. 2019.

91. Dingankar AR, Cave DA, Anand V, Sivarajan VB, Nahirniak S, Sheppard C, et al. Albumin 5\% versus crystalloids for fluid resuscitation in children after cardiac surgery. Pediatr Crit Care Med. 2018;19(9):846-53.

92. Haas T, Preinreich A, Oswald E, Pajk W, Berger J, Kuehbacher G, et al. Effects of albumin 5\% and artificial colloids on clot formation in small infants. Anaesthesia. 2007;62(10):1000-7.

93. Hanart C, Khalife M, De Ville A, Otte F, De Hert S, Van der Linden P. Perioperative volume replacement in children undergoing cardiac surgery: albumin versus hydroxyethyl starch 130/0.4 Crit Care Med. 2009;37(2):696-701.

94. Liet JM, Bellouin AS, Boscher C, Lejus C, Roze JC. Plasma volume expansion by medium molecular weight hydroxyethyl starch in neonates: a pilot study. Pediatr Crit Care Med. 2003;4(3):305-7.

95. Lynch SK, Mullett MD, Graeber JE, Polak MJ. A comparison of albumin-bolus therapy versus normal saline-bolus therapy for hypotension in neonates. J Perinatol. 2008;28(1):29-33.

96. Maitland K, Pamba A, English M, Peshu N, Levin M, Marsh K, et al. Pre-transfusion management of children with severe malarial anaemia: a randomised controlled trial of intravascular volume expansion. Br J Haematol. 2005;128(3):393-400.

97. Muller Dittrich MH, Brunow de Carvalho W, Lopes Lavado E. Evaluation of the "early" use of albumin in children with extensive burns: a randomized controlled trial. Pediatr Crit Care Med. 2016;17(6):e280-6.

98. Oliver WC Jr, Beynen FM, Nuttall GA, Schroeder DR, Ereth MH, Dearani JA, et al. Blood loss in infants and children for open heart operations: albumin 5\% versus fresh-frozen plasma in the prime. Ann Thorac Surg. 2003;75(5):1506-12.

99. Riegger LQ, Voepel-Lewis T, Kulik TJ, Malviya S, Tait AR, Mosca RS, et al. Albumin versus crystalloid prime solution for cardiopulmonary bypass in young children. Crit Care Med. 2002;30(12):2649-54.

100. Standl T, Lochbuehler H, Galli C, Reich A, Dietrich G, Hagemann H. HES 130/0.4 (Voluven) or human albumin in children younger than 2 yr undergoing non-cardiac surgery. A prospective, randomized, open label, multicentre trial. Eur J Anaesthesiol. 2008;25(6): 437-45.

101. Van der Linden P, De Ville A, Hofer A, Heschl M, Gombotz H. Six percent hydroxyethyl starch 130/0.4 (Voluven(R)) versus 5\% human serum albumin for volume replacement therapy during elective open-heart surgery in pediatric patients. Anesthesiology. 2013;119(6):1296-309.

102. Witt V, Pichler H, Beiglboeck E, Kursten F, Weidner L. Changes in hemostasis caused by different replacement fluids and outcome in therapeutic plasma exchange in pediatric patients in a retrospective single center study. Transfus Apher Sci. 2017;56(1):59-65.

103. Akech S, Gwer S, Idro R, Fegan G, Eziefula AC, Newton CR, et al. Volume expansion with albumin compared to gelofusine in children with severe malaria: results of a controlled trial. PLoS Clin Trials. 2006;1(5):e21.

104. Maitland K, Kiguli S, Opoka RO, Engoru C, Olupot-Olupot P, Akech SO, et al. Mortality after fluid bolus in African children with severe infection. N Engl J Med. 2011;364(26):2483-95.

105. Pladys P, Wodey E, Betremieux P, Beuchee A, Ecoffey C. Effects of volume expansion on cardiac output in the preterm infant. Acta Paediatr (Oslo, Norway : 1992). 1997;86(11):1241-5.

106. Gelbart B, Bitker L, Segal A, Hutchinson A, Soh N, Maybury T. Haemodynamic response to fluid boluses in children after cardiac surgery: a technical report. Crit Care Resusc. 2019;21(2):132-8.

107. George EC, Kiguli S, Olupot PO, Opoka RO, Engoru C, Akech $\mathrm{SO}$, et al. Mortality risk over time after early fluid resuscitation in African children. Crit Care. 2019;23(1):377.

108. Loeffelbein F, Zirell U, Benk C, Schlensak C, Dittrich S. High colloid oncotic pressure priming of cardiopulmonary bypass in neonates and infants: implications on haemofiltration, weight gain and renal function. Eur J Cardio-thorac Surg. 2008;34(3):648-52.

109. Greissman A, Silver P, Nimkoff L, Sagy M. Albumin bolus administration versus continuous infusion in critically ill hypoalbuminemic pediatric patients. Intensive Care Med. 1996;22(5):4959.

110. Eljaiek R, Heylbroeck C, Dubois MJ. Albumin administration for fluid resuscitation in burn patients: a systematic review and metaanalysis. Burns. 2017;43(1):17-24.

111. Bihari S, Prakash S, Bersten AD. Early changes in serum electrolytes and acid-base status with administration of $4 \%$ albumin. Intensive Care Med. 2014;40(9):1392-3.

112. Yunos NM, Bellomo R, Hegarty C, Story D, Ho L, Bailey M. Association between a chloride-liberal vs chloride-restrictive intravenous fluid administration strategy and kidney injury in critically ill adults. JAMA. 2012;308(15):1566-72.

Publisher's Note Springer Nature remains neutral with regard to jurisdictional claims in published maps and institutional affiliations. 